Why should we keep the cerebellum in mind when thinking about addiction?

*Miquel $M^{1,2}$, Toledo $R^{2}$, García $L I^{2}$, Coria-Avila $G A^{2}$, Manzo $J^{2}$

${ }^{1}$ Área de Psicobiología. Universidad Jaume I. Castellón, Spain.

${ }^{2}$ Instituto de Neuroetología. Universidad Veracruzana, Xalapa, Ver., Mexico.

Running head: cerebellum and addiction

Corresponding author:

Marta Miquel Ph.D

Área de Psicobiología. Universidad Jaume I.

12071 Castellón, Spain

miquel@psb.uji.es 


\begin{abstract}
Marta Miquel; Rebeca Toledo; Luis I Garcia ; Genaro A Coria-Avila, Jorge Manzo. Why should we keep the cerebellum in mind when thinking about addiction?
\end{abstract}

Increasing evidence has involved the cerebellum in functions beyond the sphere of motor control. In the present article, we review evidence that involves the cerebellum in addictive behaviour. We aimed on molecular and cellular targets in the cerebellum where addictive drugs can act and induce mechanisms of neuroplasticity that may contribute to the development of an addictive pattern of behaviour. Also, we analyzed the behavioural consequences of repetitive drug administration that result from activitydependent changes in the efficacy of cerebellar synapses.

Revised research involves the cerebellum in drug-induced long-term memory, druginduced sensitization and the perseverative behavioural phenotype. Results agree to relevant participation of the cerebellum in the functional systems underlying drug addiction. The molecular and cellular actions of addictive drugs in the cerebellum involve long-term adaptative changes in receptors, neurotransmitters and intracellular signalling transduction pathways that may lead to the re-organization of cerebellar microzones and in turn to functional networks where the cerebellum is an important nodal structure. We propose that drug induced activity-dependent synaptic changes in the cerebellum are crucial to the transition from a pattern of recreational drug taking to the compulsive behavioural phenotype. Functional and structural modifications produced by drugs in the cerebellum may enhance the susceptibility of fronto-cerebellar circuitry to be changed by repeated drug exposure. As a part of this functional reorganization, drug-induced cerebellar hyper-responsiveness appears to be central to reducing the influence of executive control of the prefrontal cortex on behaviour and aiding the transition to an automatic mode of control.

Key words: cerebellum, drug addiction, alcohol, morphine, cocaine, amphetamine, endocannabinoids, sensitization, conditioned emotional memories, cerebellar plasticity 


\section{THE CEREBELLUM: MORE THAN WHAT WE THOUGHT}

Very recently, Masao Ito [1] and Narender Ramnani [2] published two excellent and exhaustive reviews on the cerebellum and its functions. Both are highly recommended papers to get a broad perspective on past and current research in this topic. Surely the lesson to be learned from both articles is that later developments in cerebellar research situate functions of the cerebellum beyond motor control. The assumption that the cerebellum controls movement came from medical observations in the mid $19^{\text {th }}$ and the beginning of the $20^{\text {th }}$ century $[1,3]$. Neurologists observed that lesions in this structure resulted in difficulties in coordinating movement, and experimental physiologists showed that after removing the cerebellum a lack of motor coordination was produced. In the sixties, a specialized role for the cerebellum in the learning of motor patterns was proposed, initially in conventional motor skills and later in Pavlovian conditioning, operant learning, and in the acquisition of voluntary movements [1, 2, 3, 4]. However, more evidence, mainly from human neuroimaging studies, involved the cerebellum in functions beyond the sphere of motor control. Examples of these new roles are cerebellar involvement in emotional memory and emotional experience $[5,6,7,8,9]$, sex and orgasm $[10,11]$, language [12], planning and prediction [13], and perceptual ability [14, 15].

The focus of the present article is to review evidence that involves the cerebellum in addictive behaviour. First, we aimed on molecular and cellular targets in the cerebellum where addictive drugs can act and induce mechanisms of neuroplasticity that may contribute to the development of an addictive pattern of behaviour. Our proposal is not an exhaustive update of molecular mechanisms of addictive drugs in the cerebellum, but a description of common molecular and cellular modifications that underlie drug-induced behavioural changes. Second, we analyzed behavioural 
consequences of repetitive drug administration that result from activity-dependent changes in the efficacy of cerebellar synapses. Many of the data discussed here illustrate other examples of the involvement of the cerebellum in non-motor functions.

\section{A BRIEF DESCRIPTION OF THE FUNCTIONAL NEUROANATOMY OF THE CEREBELLUM}

The cerebellum, or little brain, is located posterior to the brain hemispheres covering the dorsal part of the brainstem, but it is not so small. The human cerebellum contains about 50 billion neurons [2]. It is a symmetrical structure with a remarkable stereotyped neuronal organization in its cortex. The dorsal view shows that its geometry is a hemispherical ellipse with the major axis in a coronal position and the minor in a sagittal position, and allows the recognition of a central region known as the vermis, with two hemispheres on each side "Fig. (1)".

The cerebellar surface appears undulated in the rostrocaudal orientation, which results from the presence of transverse fissures. Some of the transverse fissures extend until the lateral border of the cerebellum. Additionally, some of the fissures are deeper than others. The arrangement of fissures led to the recognition of 10 different lobules of the cerebellar cortex $[16,17]$ "Fig. (2)", which are composed of three different layers organized in a characteristic manner: 1) the uppermost layer is called the Molecular Layer, 2) the middle layer is known as the Purkinje Perikarya Layer, and 3) the bottom layer is referred to as the Granule Cell Layer. The neurons and axons in these layers of the cerebellar cortex are arranged in complex circuits that seem to have just one aim: the control of Purkinje neurons that constitute the only cortical output [18,19] "Fig. (3)". The first histological drawings of this arrangement were made by Santiago Ramon y Cajal [20], who described the now well-known distribution of granule and Purkinje somas and the parallel and climbing fiber inputs to Purkinje's dendritic tree. 
Cerebellar circuitry has an uniform structure and a modular organization [1]. The functional unit of the cerebellar cortex is a microzone, that refers a corticonuclear arrangement [for review see 1,18]. In 1984, Ito [21] proposed the new concept of microcomplex to describe "a combination of microzone and related subcortical structures”. So, a microcomplex consists of corticonuclear projections in a specific cerebellar region and their connections to a small group of subcortical structures including: the inferior olive, the pontine nucleus, the vestibular nucleus and the parvicellular red nucleus. The human brain may contain about 5000 of these microcomplexes.

The variation across the cerebellar cortex is negligible as compared with the scale of uniformity [2]. Therefore, it seems that the functional regionalization in the cerebellar cortex arises from the diverse nature of the inputs to the cerebellum $[2,22]$. Each microcomplex is involved in a functional network via its connections to different parts of the cerebral cortex and spinal cord $[1,21]$, the thalamus [23], the septohippocampal complex and the amygdala [7]. It has been suggested that corticalcerebellar loops work in parallel to cortical-basal ganglia loops to control behavioural output [24]. Each loop involves different subset of cerebral cortical neurons and project to the cerebral cortex via distinct thalamic nuclei $[23,24]$. Re-evaluation of earlier described anatomical data, however, suggests indirect communication between corticalbasal ganglia loops and cortical-cerebellar loops [24, 25, 26].

The anatomical pathways through which the cerebellum communicates with the prefrontal cortex and amygdala deserve special consideration to answer the question of the present review. In a recent study with healthy human volunteers [7], a single-pulse of transcranial magnetic stimulation (TMS) over the cerebellar vermis increased theta activity in the prefrontal cortex. Earlier, it was demonstrated that the electrical 
stimulation of the fastigial nucleus, which receives projections from the vermis, evoked neuronal activity in the amygdala and hippocampus [27]. Moreover, the cerebellum receives an important aminergic neuromodulation [28], including dopamine neuromodulation from the ventral tegmental area (VTA) to the vermis $[28,29,30,31]$, where dopamine transporter and axons labelled for tyrosine hydroxylase were found [32].

All these anatomical pathways locate the cerebellum within the functional systems where addictive drugs can act and produce their behavioural effects. In following sections, we describe the synaptic organization in the cerebellum and how molecular targets in the cerebellar synapses are affected by addictive drugs.

\section{CEREBELLAR SYNAPTIC ORGANIZATION AND ACTIVITY-DEPENDENT CHANGES IN SYNAPTIC EFFICACY}

\section{Cerebellar synaptic organization}

The cerebellar cortex has two main afferent pathways "Fig". (3). Mossy fiber afferents from the brainstem and spinal cord target the glomerulus at the granular layer and make synapses with granular cells. The granular cells, in turn, project to the molecular layer and excite the Purkinje cells. Within the glomerulus, the dendrites of granular cells receive excitatory synapses (mostly glutamatergic) from mossy fiber terminals and an inhibitory input (gabaergic) from the Golgi cell axons. Both AMPA and NMDA receptors mediate excitatory signals from mossy fibers to the granule cells.

A single impulse in a mossy fiber generates burst spikes in granule cells [33]. The axons of granule cells supply glutamatergic synapses to the dendritic tree of Purkinje cells before and after they bifurcate into the parallel fibers in the molecular layer [34, 35]. Excitatory responses in the dendrites of Purkinje cells are mediated entirely by nonNMDA receptors. AMPA receptors generate fast EPSPs (excitatory postsynaptic 
potentials) and the glutamate metabotropic receptor mGluR1 is responsible for slow EPSPs [36]. These slow excitatory postsynaptic potentials are facilitated by the activation of $\mathrm{GABA}_{\mathrm{B}}$ receptors expressed in the dendrites of the Purkinje cells $[1,37]$. The parallel fibers make excitatory synapses not only with the distal dendrites of the Purkinje cells, but also those of stellate and basket cells. Both are inhibitory interneurons and produce IPSPs currents in the Purkinje membrane via GABA $A_{A}$ receptors [1].

The other afferent pathway to the cerebellar cortex is the climbing fibers, which arise from the inferior oliva in the ventral part of the caudal brainstem [for review see 1]. Each Purkinje cell receives innervation from one climbing fiber, which makes several excitatory synapses with a single Purkinje neuron. The glutamatergic signal is mediated by AMPA receptors and induces a burst of impulses in the Purkinje cell known as complex spike.

Afferents segregate on the dendritic surface of Purkinje neurons creating different functional domains [38]. Granule-cell synapses are limited to the distal dendritic shafts, whereas climbing-fiber contacts are circumscribed to the proximal dendrite. Inhibitory contacts are also segregated. Basket cells make synapses on the basal part of the Purkinje soma; whereas stellate cells are restricted to dendrites [38]. The existence of the discrete extracellular domains may have important functional consequences for cerebellar networks.

\section{Activity-dependent changes in synaptic efficacy within the cerebellum}

Most of the above described synapses support activity-dependent changes in synaptic efficacy. Long-term depression (LTD) has been proposed as the major memory mechanism in the cerebellum which is related to motor [4] and perceptual learning [13]. The coincidence of parallel fiber and climbing fiber inputs is required for the 
induction of LTD [39]. LTD takes place in parallel fiber-Purkinje cell synapses when the impulses of a group of parallel fibers and one climbing fiber reach the same Purkinje neuron synchronously and repeatedly [4]. LTD is expressed as a prolonged depression of this synapse, in which a persistent decrease in postsynaptic sensitivity to glutamate is observed [39]. The convergence of parallel and climbing fiber impulses on Purkinje cells also induces activity-dependent changes in basket and stellate cells [40]. After pairing both inputs, an increase in the activation of these inhibitory interneurons was observed. Thus, two synergistic mechanisms contributed to long-term depression of Purkinje cells and the final release of the inhibition in deep cerebellar nucleus neurons: LTD in Purkinje synapses and long-term potentation (LTP) in the parallel synapses with stellate and basket cells [1]. LTP has been also found in Purkinje synapses if parallel fibers are repeatedly stimulated independent of climbing fibers [41]. Postsynaptic LTP in parallel fiber- Purkinje synapses may have a homeostatic function. Once induced, it is able to remove and reset LTD after saturation, permitting in turn a new LTD [42].

At the molecular level, LTD in the Purkinje synapses involves a complex cascade of events that can be summarized in two intracellular convergent postsynaptic pathways [for review see 1,4$]$. The activation of mGluR in parallel fiber-Purkinje synapses triggers the phospholipase $\mathrm{C}$ cascade linked to diaglicerol (DAG) and inositol trisphosphate $\left(\mathrm{IP}_{3}\right)$ as second messengers. DAG activates protein kinase $\mathrm{C} \alpha(\mathrm{PKC})$ and $\mathrm{IP}_{3}$ generates $\mathrm{Ca}++$ release from intracellular stores. It has been also observed that nitric oxide (NO) and cyclic GMP cascade is part of the same molecular pathway [43]. The second intracellular response depends on the release of glutamate in climbing fibersPurkinje synapses, which activates postsynaptic AMPAR and produces an increase in $\mathrm{Ca}++$ current through voltage-gated $\mathrm{Ca}++$ channels. The convergence of mGluR- and AMPAR-dependent intracellular cascades induces the internalization of AMPAR by 
endocytosis. Cerebellar LTD shows, therefore, specificity in two features as compared with other parts of the brain. First, as Purkinje neurons do not express NMDA receptors the induction of both LTD and LTP wholly depend on AMPA and mGluR receptors. Second, both mechanisms rely on intracellular $\mathrm{Ca}++$ concentrations, but in the opposite manner as described for other brain structures. A high $\mathrm{Ca}++$ levels facilitate LTD, whereas a low $\mathrm{Ca}++$ concentration directs the process towards LTP [1].

Recently, the involvement of retrograde endocannabinoid signalling in activitydependent synaptic plasticity has been described [for review see 44, 45]. This retrograde mechanism mediates both short-term and long-term synaptic changes in the cerebellum, basal ganglia, amygdala, VTA and neocortex. Briefly, postsynaptic activation of glutamatergic receptors elicits the synthesis of a lipid endocannabinoid messenger, very probably: (2-arachidonoylglycerol (2-AG) that once released in the synaptic cleft, moves in a retrograde direction, binds to presynaptic $\mathrm{CB}_{1}$ receptors and suppresses excitatory and inhibitory neurotransmitter released by the pre-synaptic neuron. The suppression of excitatory input is named depolarization-induced suppression of excitation (DSE) and the one which suppresses the release of inhibitory neurotransmitter is known as depolarization-induced suppression of inhibition (DSI) $[46,47,48]$.

The cerebellum expresses a high level of $\mathrm{CB}_{1} \mathrm{R}[49,50]$, but also $\mathrm{CB}_{2} \mathrm{R}[51]$. Molecular events that trigger endocannabinoid-mediated short-term synaptic changes in the cerebellar cortex are shown to be both dependent and independent on $\mathrm{Ca}^{2+}$ current flowing into the postsynaptic cell. The $\mathrm{Ca}^{2+}$-independent mechanism is induced by the activation of mGluR and the phospholipase $\mathrm{C}$ intracellular cascade [52]. At the presynaptic level, $\mathrm{CB}_{1} \mathrm{R}$ activation in the climbing and parallel terminals produce a 
decrease in the $\mathrm{Ca}^{2+}$ current into the terminal and a decrease in EPSC amplitude [53, 54].

Activity-dependent long-term changes in the efficacy of cerebellar synapses are also mediated by an endocannabinoid-dependent retrograde mechanism [55]. The repeated coincidence of parallel fiber and climbing fiber inputs triggers an enhancement of $\mathrm{Ca}^{2+}$ influx to the Purkinje neuron, mGluR postsynaptic activation and the endocannabinoid release to the synaptic cleft. The induction of cerebellar LTD requires the activation of pre-synaptic $\mathrm{CB}_{1} \mathrm{R}$, but once induced, LTD maintenance is independent on $\mathrm{CB}_{1} \mathrm{R}[44,55]$. The administration of a $\mathrm{CB}_{1} \mathrm{R}$ antagonist or the deletion of the $\mathrm{CB}_{1} \mathrm{R}$ gene abolishes cerebellar LTD [55].

\section{THE CEREBELLUM HAS MANY MOLECULAR TARGETS WHERE ADDICTIVE DRUGS CAN ACT AND INDUCE NEUROPLASTICITY MECHANISMS}

Activity-dependent changes in synaptic efficiency seem to be crucial to experience-dependent modification of brain functions, but also drug-induced long-term modifications. Drug-induced long-term changes have been proposed as the substrate of addictive behaviour $[56,57]$. Thus, the compulsive phenotype of drug-seeking and drug-taking behaviour, the relapse after withdrawal and the loss of control over drug use are all aspects of addictive behaviour that result from the "re-wiring" of motivational circuitry after repeated exposure to drugs [58].

For many years, research into the cellular mechanisms of neuroplasticity induced by drugs has focused on dopamine release in the basal ganglia and associated intracellular signalling pathways [59]. It has been demonstrated, however, that complex interactions between glutamatergic inputs to the basal ganglia and the dopamine system are critically involved in this long-term drug-induced neuroplasticity $[58,59,60,61,62$, 
$63,64,65]$. Now it is well-known that changes in glutamate transmission, including alterations in the structure and function of glutamate receptors and glutamate release mediate the effects of addictive drugs $[58,59,64,65,66,67,68]$. The stimulatory effects of drugs of abuse on locomotion and the subsequent progressive increase in this effect known as sensitization are both regulated by ionotropic (iGluR) and metabotropic (mGluR) glutamate receptors in the glutamate synapses of the nucleus accumbens (Nacc) and the ventral tegmental area (VTA) $[65,66,67,68]$. Moreover, modifications of postsynaptic proteins associated with glutamate intracellular signalling pathways were shown to be linked to drug-induced neuroplasticity and to contribute to the uncontrollable drive to seek drugs $[61,62,63,69,70,71]$.

In addition, recent findings support the participation of the endocannabinoid system in the common neural networks underlying drug-induced neuroplasticity and thereby, drug addiction [71]. The endocannabinoid retrograde control has been observed after synaptic activation of glutamate and dopamine receptors $[73,74] . \mathrm{CB}_{1}$ receptors modulate excitatory and inhibitory inputs to mesolimbic and mesocortical dopamine systems, and local neuroplasticity mechanism as LTD $[72,74]$. The involvement of the endocannabinoid system in drug addiction is supported by pharmacological and knockout studies, which show that self-administration of nicotine, alcohol, heroin and morphine is decreased under $\mathrm{CB}_{1}$ antagonism or in $\mathrm{CB}_{1}$ receptor knockout mice $[75,76$, 77, 78, 79]. Also, drug-induced conditioned affective memories are altered under $\mathrm{CB}_{1}$ deletion or pharmacological blockade [77, 80].

As illustrated in the previous section, short-term and long-term plasticity in the cerebellum seems to be mediated by glutamate and endocannabinoid-dependent cellular mechanisms. Additionally, it is known that the vermis of the cerebellum received dopaminergic projections from the VTA $[28,29,30,31]$. Therefore, within the 
cerebellum the above-described interactions among dopamine, glutamate and endocannabinoid systems may be affected by drugs of abuse and contribute to adaptations leading to addiction.

\section{Molecular targets and drug-induced plasticity mechanism in the cerebellum}

\section{Ethanol}

The cerebellar cortex has numerous molecular targets where ethanol can act and stimulate or inhibit plasticity mechanisms "Fig. (4)". Several studies have shown that ethanol modifies both pre-and post-synaptic features of glutamatergic transmission [81].Various glutamate receptor subtypes have been shown to be affected by ethanol at different concentrations [81]. Acute alcohol at high concentrations $(30-100 \mathrm{mM})$ depresses $\mathrm{Ca}^{2+}$ signalling linked to AMPA/Kainate receptors activation in dendritic and somatic Purkinje cell regions [82]. However, chronic ethanol exposure enhances AMPA-elicited $\mathrm{Ca}^{2+}$ currents in the same regions of Purkinje cells [83]. Both studies suggest that the actions of ethanol on $\mathrm{Ca}^{2+}$ signalling through AMPAR could underlie the rapid effects of ethanol on behaviour, because AMPAR mediates fast excitatory neurotransmission [81]. In contrast, ethanol at lower concentration $(10 \mathrm{mM})$ enhances $\mathrm{Ca}^{2+}$ current to mGluR agonists in Purkinje somas and dendrites [81]. It is possible therefore that $\mathrm{Ca}^{2+}$ signalling from multiple glutamate receptors in the cerebellar cortex underlies the behavioural effects of different ethanol doses.

It has been also observed that ethanol modulates neural responsiveness to GABA and alters $\mathrm{GABA}_{\mathrm{A}}$ receptor function and expression of $\mathrm{GABA}_{\mathrm{A}}$ receptor subunits [84]. Ethanol acutely increases GABAergic transmission in the glomerulus at the granular layer and contributes to the inhibition of mossy fiber-mediated excitation [84]. The GABA increase is mediated in part by the enhancement of spontaneous firing of Golgi cells that supply GABA inhibition within the glomerulus, which is produced by ethanol 
[85]. In addition, acute ethanol enhances the inhibitory action of GABA on Purkinje cell activity and suppresses spontaneous Purkinje cell discharge [86]. Chronic ethanol, nevertheless, reduces the responsiveness of cerebellar granule cells to exogenously applied GABA [87]. Ethanol-induced GABA depression of the Purkinje cells may involve nicotinic receptors in these cells, because it is boosted by co-application of nicotine and suppressed by nicotine antagonism [88]. Taken together, it is possible to conclude that whereas acute ethanol reduces the excitability of cortical cerebellar circuitry, its chronic presence leads to the hyperexcitability of cerebellar neurons.

Ethanol also influences cerebellar intracellular pathways associated with glutamate transmission $[81,82]$. By activating the intracellular signal transduction pathway of the serine/theorine kinase known as mitogen-activated protein kinase (MAPK) or extracellular signal regulated protein kinase (ERK), glutamate receptors control transcriptional activity and protein synthesis in response to drugs and thus, plasticity mechanisms leading to addiction [56]. Continuous regimen of ethanol treatment reduces the levels of ERK activation in the cerebellum, amygdala, hippocampus and cerebral cortex. On the contrary, intermittent exposure to ethanol upregulates the MAPK-ERK pathway during withdrawal periods in the amygdala and cerebellum [89]. It has been shown that activations of the ERK pathway increase CREB-dependent transcription of an associated family of genes [56]. Moreover, CREBmediated transcription is reported to be necessary for activating long-term plasticity genes [90]. In accordance, ethanol increases CREB levels in the cerebellum and this effect requires protein kinase A (PKA) and adenosine receptor activation (A2) [91]. Supporting the idea that ethanol produces cerebellar long-term plasticity, it has been recently demonstrated that ethanol affects dynamic modulation of the actin 
cytoskeketon in this structure [92]. Actin remodelling has been described as a crucial step for long-term memory storage in the hippocampus and other parts of the brain [93]. Cannabis sativa

To our knowledge few studies have approached molecular or electrophysiological modifications induced by Cannabis sativa in the cerebellum "Fig. (4)". Gonzalez el al. (2004) reported an increase in 2-AG (2-arachidonoylglycerol) in the cerebellum of chronic delta 9-tetrahydrocannnabinol-treated rats as compared with controls [94]. Chronic delta-9-THC (the major psychoactive component of cannabis sativa) administration prevents the increase in the ERK pathway produce by acute delta9-THC administration [95]. However, after withdrawal an up-regulation of adenylcyclase activity [96] and a downstream enhancement of the cAMP-PKA pathway [97] are both observed. Changes in CREB expression can be seen in granule cells at granular layer of the cerebellum after delta-9-THC treatment. Acute delta-9-THC increased CREB immunostaining and protein expression, although a significant decrease in CREB was observed in chronically treated rats. The decrease still persisted 3 weeks after withdrawal [98].

Additional data demonstrated that the endocannabinoid system mediates actions and plasticity changes induced by other drugs of abuse in the cerebellum. For example, the endocannabinoid system seems to be involved in molecular mechanisms of ethanol and morphine. Chronic ethanol or morphine exposure to cultures of cerebellar granule cells produces accumulation of 2-arachidonylglycerol and arachidonylethanolamide (AEA) $[99,100,101]$. The synthesis of these endocannabinoids increases proportionally to the duration of the ethanol exposure and is prevented by $\mathrm{CB}_{1}$ antagonist [100]. Also, the density of $\mathrm{CB}_{1}$ receptors could be reduced by both drugs in the cerebellum, but a 
recovery at the basal levels is observed after 24 hours of withdrawal from ethanol [100, $101]$.

Psychostimulants

Although the cerebellum has relatively low dopamine innervation, it is known that VTA sends DA projections to the vermis [28, 30, 31]. In accordance, dopamine transporters and axons labelled for tyrosine hydroxilase have been found in the vermis [32]. As should be expected, cocaine and amphetamine increase Fos-like immunoreactivity in the rat granular layer of the vermis at a wide range of doses and, occasionally in Purkinje neurons [102] "Fig. (4)". It is believed that this effect depends on D1 receptors, given the evidence that a D1 selective antagonist totally blocks psychostimulant-induced Fos immunoreactivity [102]. Furthermore, in nonhuman primates mapping DA function with amphetamine demonstrated an increase in the relative cerebral blood volume in the dentate nucleus of the cerebellum, along with increases in structures of the cortico-striatal-thalamic-limbic system [103]. Recordings of extracellular activity in the cerebelar cortex showed that cocaine is able to suppress spontaneous firing and glutamate-induced activation of Purkinje cells [104]. It would appear that cocaine-induced inhibition of these cells is mediated by a DA-independent mechanism. Both spontaneous firing and glutamate-dependent suppression are blocked with yohimbine, an $\alpha_{2}$-adrenoreceptor antagonist [104]. Thus, it is very likely that the mechanism underlying the effect of cocaine on Purkinje neurons is the inhibition of noradrenaline transporters at synapses neuromodulated by noradrenergic fibers from the locus coeruleus [104].

One of the neuroadaptations that has been recently confirmed in the Purkinje soma and dendrites after cocaine administration is the augmented expression of Homer $1 \mathrm{~b} / \mathrm{c}$ and $3 \mathrm{a} / \mathrm{b}$ [104]. These long homer isoforms are a crucial link between mGluR and 
$\mathrm{IP}_{3}$-dependent intracellular $\mathrm{Ca}^{2+}$ signalling, and they are considered as an important step of synaptic remodelling and spine morphogenesis [105, 106, 107].

To sum up, the molecular and cellular actions of addictive drugs in the cerebellum involve long-term adaptative changes in receptors, neurotransmitters and intracellular signalling transduction pathways that may lead to the "re-wiring" of [58] cerebellar microzones and in turn change functional networks where the cerebellum is involved.

Several of the above-mentioned drug-induced molecular changes have been correlated with drug tolerance, drug dependence and the withdrawal syndrome $[94,95$, $96,97,98,100,101,108]$. In general, acute drug administration increases receptors, neurotransmitters and intracellular signalling transduction responses in the cerebellum. Compensatory changes during chronic treatment lead to an apparent normalization of these initial modifications, but after drug withdrawal alterations in cerebellar parameters can be seen again. It is important to note that intermittent drug administration can exacerbate plasticity changes observed during wash-out periods.

Homeostatic adaptations that may occur within cells and circuits after repeated stimulation by addictive drugs were once believed to be cardinal symptoms of addiction [109]. It is now recognized that they are neither necessary nor sufficient for a person to be addicted $[56,57,109,110,111,112,113,114]$. The chief argument for this new perspective is that the risk of relapse remains high long after drug withdrawal. Thus, the new point of view about addiction involves both a compulsive pattern of drug consumption and the high risk of relapse as major symptoms of the addiction illness. This current view proposes that the compulsive phenotype of drug-seeking and drugtaking behaviour and relapse are both aspects of addictive behaviour that result from drug-induced long-term changes which re-wire motivational circuitry [56, 57, 58]. 
Neuroadaptations as sensitization and associative memory mechanisms are now considered crucial processes to explain addiction.

In the next sections, we analyze the involvement of the cerebellum in druginduced sensitization and review animal and human data involving the role of cerebellum in conditioned memory, which may contribute to the development of a compulsive behavioural phenotype and the relapse of drug taking.

Table (1).

\section{DRUG-INDUCED MOLECULAR AND CELLULAR CHANGES IN THE CEREBELLUM ARE RELATED TO SENSITIZATION}

It is known that drug-induced modifications of the interactions between dopamine and glutamate systems, including changes in the structure and function of receptors and associated intracellular pathways, trigger a cascade of neuroadaptations underlying acquired increases in sensitivity to the behavioural effects of addictive drugs $[58,60,65,66,111,112,113]$. Behavioural sensitization thus refers to the progressive increase in behavioural responses to drugs that is developed during repeated drug administration and that persists after long periods $[65,112]$. Plasticity changes such as LTP in the cell-body region of the mesolimbic dopamine systems, the VTA of the midbrain, are crucial to elicit the hyper-excitability of DA neurons that triggers the development of drug-induced sensitization [115]. Long-term depression, but also LTP in the nucleus accumbens, however, seem to mediate the expression of behavioural sensitization [116].

The relevance of sensitization for the development of addiction has been suggested by the theory of Incentive Salience $[111,112,113]$. It proposes that as a consequence of long-term changes in the dopaminergic system the incentivemotivational ability of drug-associated cues is sensitized and contributes to intensify 
drug craving and drug seeking. Sensitization could also reinforce associations between conditioned cues and drug effects leading to the strength of conditioned memories, which in turn could trigger drug seeking and drug taking $[110,117]$. All drugs with an addictive potential produce sensitization [113], but not all of the drug effects sensitized. In general, one can observe that drug-induced behavioural activating effects are those that develop a progressive augmentation $[112,113]$. The simplest way to asses if an animal sensitized is testing its locomotor activity during repeated administration of the drug. The progressive increase in locomotor activity and the significant difference between the first and the last day of drug treatment show the sensitization of the drug effect.

\section{Drug sensitization and cerebellar plasticity}

Still few but consistent data demonstrate that the cerebellar cortex plays a key role in the neuroadaptations leading to behavioural sensitization. The cerebellum is a central site for the molecular mechanisms of 9-delta-THC sensitization [118]. 9-deltaTHC sensitized rats show an increase in $\mathrm{CB}_{1}$ receptor binding restricted to the cerebellar cortex, with no appreciable alteration in other brain areas that also have a high density of $\mathrm{CB}_{1}$ receptors [118]. Since previous reports revealed that $\mathrm{CB}_{1}$ down-regulation correlates with the development of 9-delta-THC tolerance [119], the increase in the binding seems to be a specific adaptation underlying sensitization. In Rubino's study [118], the increase in $\mathrm{CB}_{1}$ binding was accompanied by an enhancement of $\mathrm{G}$ protein coupling and the lack of alteration in the response of the cAMP pathway to cannabinoids agonists in sensitized rats.

Repeated and intermittent ethanol exposure sensitizes locomotion [120, 121 122]. Very few studies, however, have been performed to evaluate cerebellar plasticity changes in animals sensitized to alcohol. It has been shown that the intermittent regimen 
of ethanol treatment activates phosphorylated ERK that peaks 24 hours post-withdrawal in the rat cerebellum and amygdala [89. In our laboratory, very recently, we observed high significant but inverse correlations between ethanol-induced locomotor sensitization and the number of new proliferated cells (Brd-U+) induced by environmental enrichment at the granular layer of the lobules IX $(r=-0.58 ; \mathrm{p}<0.01)$ and $X(r=-0.63 ; p<0.001)$ in the mouse vermis. Furthermore, sensitized animals showed significantly less immunoreactivity for Brd-U at the granular layer than animals not sensitized but treated with the same regimen of alcohol (data presented at the SfN Meeting 2007 San Diego. Abstract online: 909.12/EE24).

Sensitization to cocaine has been also associated with several cerebellar molecular changes. Chronic administration of cocaine that induces locomotor sensitization also increases the binding of MK-801, a NMDA antagonist, in the cerebellum [123]. Furthermore, cocaine-induced sensitization has been related to an increase in nitric oxide synthase activity in this structure [124], supporting behavioural data that showed the blockade of cocaine-induced locomotor sensitization by NOS inhibitors $[125,126]$. Finally, sensitization of c-fos and jun-B mRNA has been demonstrated in the cerebellar cortex of cocaine sensitized rats [127]. This effect is mediated by D1, D2, GABA $\mathrm{B}$ and NMDA cerebellar receptors.

Further research is required to describe and explain the precise role of cerebellar plasticity in sensitization produces by addictive drugs. It is important to elucidate if the involvement of the cerebellum in drug-induced sensitization is general for all druginduced sensitized effects, or rather, if it is restricted to locomotion, since lobules IX and $\mathrm{X}$ are directly involved in the control of locomotor functions [128]. It would be of interest, for example, to test if the cerebellum is implicated in the sensitization of the incentive salience effect. We feel that it could be the case, since as we describe in the 
next section the cerebellum seems to be a relevant structure to store long-term emotional memories.

\section{CONDITIONED EMOTIONAL MEMORIES IN THE CEREBELLUM}

Addictive drugs induce synaptic modifications in brain functional networks that support Pavlovian and instrumental memories [110]. Contemporary theories of addiction ascribe special relevance to drug-associated memories in inducing subjective craving, the compulsive phenotype of behaviour and relapse [110, 111, 112, 113]. Through a pavlovian associative mechanism, external stimuli that repeatedly occur in time and space closely with the effect of drugs are associated or conditioned to drug effects, and thus gain incentive salience [110]. Incentive salience requires a drug-paired conditioned stimulus to be able to reactivate emotional memories associated with drug, and instrumental memories which trigger responding to obtain the drug. Under some environmental circumstances, a conditioned cues may produce subjective drug craving in humans (animal models of craving remain controversial). For example, drug craving is provoked if there is a withdrawal condition or an obstacle to obtaining the drug [129]. However, if drugs are continuously available cues can automatically trigger drug seeking and drug taking behaviours [110].

Pavlovian and instrumental conditioned memories are controlled and stored by dopamine-glutamate interactions in the shell and core of Nacc, basolateral amygdala, hippocampus and prefrontal cortex $[110,130]$. The occurrence of a drug conditioned cue produces fast phasic burst firing of VTA dopamine projections that modulates the signal transmission of glutamatergic afferents to basal ganglia, amygdala and prefrontal cortex [131]. Dopamine signalling facilitates and strengthens long-term plasticity changes in these brain regions. DA is also released in a tonic manner [131]. It is 
believed that tonic mode is required for activation and effort-related processes on voluntary behaviour [132].

\section{Involvement of the cerebellum in drug-conditioned memories of human addicts}

Almost nothing is known about the contribution of DA signalling and DAglutamate interactions in the cerebellum. However, several human neuroimaging studies involve the cerebellum, specially the vermis, in the reactivation of drug-conditioned emotional memories $[133,134,135,136,137,138]$. Positron emission tomography (PET) and functional magnetic resonance imaging (fMRI) studies show increased glucose metabolism elicited by cocaine-and ethanol-conditioned cues in the cerebellum $[133,135,136,137,138]$. Grant et al., (1996) demonstrated that the paraphernalia associated with cocaine taking increased activation of the dorsolateral prefrontal cortex, the amygdala, and the cerebellum [133]. Interestingly, this pattern of activation was not observed for neutral videotapes. Later, they showed that when cocaine addicts listened to an evocative script that described in detail physiological and psychological sensations associated with cocaine use, the right cerebellum was also activated [136]. A very recent report confirms these results and shows regionalized activation within the vermis. Cocaine- associated cues elicit greater increases in activation of lobules II, III, VIII, and IX [25]. Olfactory stimulation with ethanol in alcoholic patients under detoxification, but not in normal healthy controls, activates the right amygdala, hippocampus, insula and cerebellum [137]. Again, the cerebellar activation was not observed for neutral cues (in this case ambient air), which is important because it precludes the possibility that the cerebellar activations are due to sensorial or motor processing no related to drug experience.

Moreover, in two studies, ratings of subjective craving correlated with cerebellar activations $[133,137]$. The correlation between cerebellar activity and subjective 
craving is lost if auditory cues are used [136]. It is difficult to explain this inconsistent result, because the cerebellum has been implicated in auditory [14] and language processing [12]. It is particularly interesting that after 3-weeks of therapeutic intervention alcoholic patients showed reductions in subjective craving, accompanied by reductions in the cerebellar activity [137]. Therapeutic training, hence, seems to reorganize emotional memory networks where the cerebellum is a crucial node, or at least, is able to produce transient extinction-like effect in this network.

Expectations are a central cognitive process in reward induced behaviour [135]. The expectation of the drug effect is shown to modulate drug-associated responses in animal models of drug consumption [139, 140]. For example, dopaminergic activations are larger when animals are treated with cocaine in an environment where they previously received cocaine as opposed to a novel environment [139]. Also, cocaine induces greater dopamine release when it is self-administered when compared to yoked administration [140]. In accordance, Volkow et al., (2003) [135] observed larger increases in cerebellum and thalamus glucose metabolism when cocaine addicts expected to receive drug and received it as compared with when they expected placebo and received drug. Self-reports of feeling "high" were also larger when expectations were generated, but surprisingly "high" ratings did not correlate with cerebellar activity increases. Authors suggested that the subjective experience of feeling high is related to the effect of psychostimulants in the basal ganglia.

Conscious memory retrieval provoked by a cocaine themed interview correlates with larger activation in the cerebellum, amygdala, orbitofrontal, cortex, and insular cortex as compared with a neutral themed interview [138]. In this case and in contrast to studies where cocaine or alcoholic patients were presented with videotapes, odours, or slides, subjective craving did not correlate with cerebellar activity, perhaps because in 
this study, subjects had to retrieve explicit episodic memories to answer in the interview.

Taken together, human studies on drug-conditioned memories involve the cerebellum in both explicit and implicit memory. These are in accordance with other studies that demonstrate a cerebellar role in the consolidation of emotional aversive

memory in rodents [5, 6]; cognitive procedural learning consolidation [141] or episodic memory encoding in humans [142].

\section{Cerebellar regionalization in memory storage}

The cerebellar regionalization of memory-related activations deserves special consideration. The vermis appears to be important for emotional memory, no matter what kind of emotional valence the stimulus presents: appetitive $[25,136,138]$ or aversive $[5,6]$. The recall and consolidation of conditioned emotional memories, therefore, memories that are reactivated in an automatic or implicit mode, seems to be controlled, in part, by the vermis $[5,6,25,136]$. During cognitive procedural learning it has been observed that different regions of the cerebellum are activated depending on the phase of the learning. The vermis is only activated in the automatic phase [141]. Explicit memory recall or encoding phase, however, seems not to involve the vermis, but cerebellar hemispheres [141, 142].

Probably the key question is which cerebral functional networks are connected to each part of the cerebellum. Electrical stimulation of the fastigial nucleus, which receives projections from the vermis, evoked neuronal activity in the amygdala and hippocampus [27]. Additionally, the vermis connects to dopamine neurons in the VTA and substancia nigra $[24,26]$ and the VTA sends dopaminergic projections to the vermis $[26,28,30,31]$, forming a reciprocal midbrain to cerebellar circuit. Ventral Tegmental projections bifurcate and send efferents both to the cerebellum and to the 
prelimbic cortex , anterior cingulate cortex and entorhinal cortex $[24,26]$. As a result of its connections, therefore, the vermis seems to be part of the circuit that sustains emotional memory and emotional behaviour. Since there is almost no causal study to investigate the role of the cerebellum in conditioned memory, further animal research is crucial to implicate the cerebellum in the emotional memory circuitry.

\section{THE ROLE OF THE CEREBELLUM IN MOTIVATED BEHAVIOUR}

A central symptom of addiction illness is inadequately managed motivated behaviour [62]. Addicts show an uncontrollable drive to seek drugs and show a decreased incentive to seek non-drug rewards. As a consequence of repeated use of addictive drugs, brain systems controlling motivated behaviour are re-organized in a way that competes with plasticity induced by natural rewards, reducing the probability of natural rewards to activate goal-directed actions [62].

Goal-directed behaviour is tuned by instrumental or reinforced learning so behaviour can adapt to environmental and internal demands. By repeated experience, reinforcers increase the probability of the response that lead to seeking them. Instrumental learning, then, by selecting responses that allow access to the reinforcer produces an adaptive reduction in the behavioural repertory and initiates the transition from behaviour controlled by their consequences to stimulus-driven habits. Acquisition, storage, reactivation even reconsolidation of instrumental memories all involve a crosstalk between the prefrontal cortex and basal ganglia, specially the Nacc and dorsal striatum [110]. Three functional networks have been recognized to control the transition from goal-directed behaviour to habit: the limbic network, the associative network and the sensorimotor network [143]. The limbic network is involved in the process of instrumental learning that is, learned behaviour controlled by their consequences or goal-directed behaviour. However, habit formation requires a shift of the activation 
from the prefrontal cortex-dorsomedial striatum circuit (associative network) to sensorimotor cortices-dorsolateral striatum circuit (sensorimotor network).

Everitt and Robbins [110] have suggested that as normal brain mechanisms of learning and memory are challenge by addictive drugs, motivational impact of drugassociated stimulus is strengthened leading to the transition from instrumental memories to inflexible drug-seeking habit formation. The progression from a ventral to a dorsolateral stream may be facilitated by dopamine signalling. Thus, as dopamine neuron activity sensitizes the transition from a goal-directed drug-induced behaviour to compulsive drug-seeking is expected to be favoured [110]. This process also depends on the executive control of the prefrontal cortex. Human and animal studies have emphasized the importance of the prefrontal cortex for behavioural flexibility. For example, there are similarities between patients with prefrontal lesions and drug addicts $[144,145]$. Both display an inflexible behaviour and frequently are not aware of the risk of incurring future negative outcomes [145]. In addition, human addicts show a reduction in the prefrontal activation when they are tested during abstinence periods, but also show a hyper-responsiveness of the prefrontal cortex when they are challenged with the drug $[146,147]$. Finally, animal studies demonstrate that lesions of the prefrontal cortex impair extinction of drug consumption [144]. The same result is observed if the lesion is restricted to the mesocortical dopaminergic system [144], which has been proposed as being the system which signals when the goal representation should be updated to activate a new response [148].

\section{Fronto-cerebellar circuitry and drug addiction}

As reviewed above, the cerebellum has reciprocal connections to functional circuitry responsible for motivated behaviour. Fronto-cerebellar circuits deserve special consideration in the present discussion because it involves the cerebellum in the system 
for the executive control of voluntary behaviour. Nonhuman primate studies have shown two dissociated fronto-cerebellar contralateral circuits: one circuit presents reciprocal connections between motor cortices and cerebellum, and the other has prefrontal-cerebellum reciprocal projections [149].

Ito has proposed that the prefrontal cortex and cerebellum work in parallel [1, 150]. As a consequence of cerebellar plasticity, an internal model of prefrontal representation is created in the cerebellum. This internal model is a copy of the information stored in the prefrontal cortex. Thus, the cerebellum may act in parallel to the prefrontal cortex and be recruited when automatic processing and activation of voluntary behaviour is required. Hence, it may be expected that the cerebellum is crucial to consolidate and perform automatic goal-directed behaviour, and to contribute to the transition from instrumental behaviour to habits. In addition, it may be possible that the prefrontal cortex and the cerebellum do not correlate in their activity, especially when initial and final phases of learning are compared.

Research aimed the role of the cerebellum in goal-directed behaviour is still in its infancy. In a recent article, Callu et al (2007) showed a dissociation of the behavioural effects of lesions in the vermis versus lesions in the interpositus nucleus [151]. They found that neither the vermis nor the interpositus nucleus lesions affected the learning process of an instrumental task. However, a bilateral lesion in the interpositus nucleus prevented development of habits with overtraining, whereas bilateral lesions of the vermis did not. Nevrtheless, rats with bilateral lesions of the vermis showed a delay in behavioural inhibition during extinction trials, although they extinguished after three extinction trials. As expected, these results suggest that the integrity of the cerebellum is not critical to learning and performing instrumental goaldirected behaviour, but is a key node in the process underlying habit behaviour. Data 
from this study support previous reports that involved the vermis in perseverative behaviour and behavioural inhibition [152]. It is interesting that adult animals that received vermix lesions when young showed perseverative behaviour in adult age, lack of attention to environmentally novel stimuli and behavioural disinhibition, a behavioural phenotype very similar to that seen after prefrontal lesions [145] or in rats engaged in chronic drug consumption [153].

Human studies with drug addicts have found analogous results. Hester and Garavan (2003) studied GO-NOGO response inhibition tasks in cocaine users and detected worse perseverance inhibition in this group than in control subjects. As working memory demands increased, cocaine users showed non-responsiveness of anterior cingulate cortex accompanied by over responsiveness of the left cerebellum [154]. Cerebellar activation correlates inversely with performance. Nonetheless, an inverse pattern was seen in normal subjects. As demands increase, control subjects have over-activated cingulate cortices and prefrontal regions but cerebellar activation remains neurtral $[154,155]$. In alcoholics, a similar pattern has been observed, but in this case the over-activity was detected in the right cerebellum [156].

Research into executive control in marijuana abusers strongly support the participation of the cerebellum in the executive function affected by drugs [157]. In the Iowa Gambling Task, marijuana abusers perform as prefrontal lesioned patients, drug addicts and pathological gamblers do [157]. All groups are hypersensitive to immediate rewards (disadvantage cards) and less sensitive to losses. Moreover, they learn from their previous mistakes slowly. Interestingly, this characteristic behaviour was correlated with a specific brain activation pattern, which resembles findings of studies with cocaine users and alcoholics: less activation in the orbitofrontal and dorsomedial cortices along with greater activation in the cerebellum. Smokers and non-smokers also 
show differences in the pattern of brain activation when they are involved in a reward task [158]. The most apparent characteristic of smokers is an increase in the activity of the cerebellum during monetary and nonmonetary reward which contrasts with a wider pattern of activation in non-smokers, including striatum, and prefrontal and limbic cortices.

Overall, the above-discussed results suggest that prefrontal and cerebellar nodes in the prefrontal-cerebellar loop are recruited in a competitive manner. In nonpathological individuals, when cognitive demands are high prefrontal executive control is activated. When an automatic and rapid response is required, however, the cerebellum increases its activity and prefrontal cortex activity reduces its activation. Anderson and co-workers [25] suggested that the relevance of the cerebellar vermix to modulate rewarding and incentive related stimuli will be increased when the frontal lobes are compromised by disease or chronic drug use. Indeed, in addict subjects, prefrontalcerebellar competition is also observed but is expressed in a converse manner. During high task demands over-activity is seen in the cerebellum, but non-responsiveness could be observed in prefrontal and limbic cortices. It seems that in addicts and heavy drug users the cerebellum controls functions normally managed by the prefrontal cortices. However, the cerebellum does not produce behavioural flexible executive control, but a rapid and automatic form of control. Perhaps, it is a part of the explanation why addicts show impairment in executive function and perseverative behaviour.

What could be the origin of such a role reversal? The answer to this question requires further experimental animal studies. Tentatively, we suggest that drug-induced cerebellar neuroplasticity, (e.g. sensitization of molecular parameters), may induce cerebellar hyper-responsiveness, where the vulnerability of the prefrontal cortex to be depressed by drugs of abuse is enhanced. Also, it is possible that drug-induced hypo- 
frontality smoothes the progress of cerebellar over-activation by drugs, or perhaps both processes could be produced in parallel.

\section{CONCLUSIONS AND SUGGESTION FOR FURTHER RESEARCH}

When we entitled this article: Why should we keep the cerebellum in mind when we thinking about addiction? Our proposal was to answer this question within the frame of reference of contemporary addiction theories. It is known that previous papers involved the cerebellum in drug-induced tolerance and dependence, but as we discussed, addiction is more than a physical dependence. The current view of addiction includes the compulsive phenotype of consumption and relapse after withdrawal as crucial symptoms of the disorder. Drug-induced long-term memory and sensitization of the incentive salience have been proposed as being required to induce the compulsive phenotype of behaviour and relapse. Research revised in the present paper involves the cerebellum in drug-induced long-term memory, drug-induced sensitization and the perseverative behavioural phenotype. Also, results support the previous suggestion that the cerebellum seems not to be important for acquiring learned behavioural patterns, but the long-term storage of procedural memories. Altogether, data agree to the relevant participation of the cerebellum in the functional systems underlying drug addiction. Because the cerebellum is decisively interposed to relate processing of exteroceptive and interoceptive stimuli to action [25], drug-induced "re-wiring" [58] of cerebellar circuitry may produce decisive functional consequences for behaviour.

As a working hypothesis, we propose that drug induced activity-dependent synaptic changes in the cerebellum are central to transit from a pattern of recreational drug taking to a compulsive behavioural phenotype "Fig. (5)". Functional and structural modifications produced by drugs in the cerebellum may enhance the susceptibility of fronto-cerebellar circuitry to be changed by repeated drug exposure. As a part of this 
functional reorganization drug-induced cerebellar hyper-responsiveness appears to be central to reduce the influence of executive control of the prefrontal cortex on behaviour and to transfer to an automatic mode of control. Thus, we can expect the characteristic patterns of cerebellar hyperactivity and prefrontal hypoactivity to follow a temporal gradient, the cerebellum being more important as the exposure to drugs is repeated. In spite of all the above-mentioned data, research into the role of the cerebellum in addiction is still in its beginnings. There are few causal studies in which cerebellar parameters are manipulated. Most of the studies have been developed with human addicts and show no more than correlations between cerebellar activity and several symptoms of the addictive illness. This approach is essential for testing results obtained in animal models and has an undoubted heuristic value. Nevertheless, an adequate description and explanation for the cerebellar participation in the compulsive behavioural phenotype of consumption requires further animal studies to clarify if the cerebellum is implicated in the sensitization of the incentive salience effect and in the transition from a pattern of recreational drug taking to the compulsive behavioural phenotype. In this sense, it is crucial to depict how the cerebellar storage of long-term memory contributes to this transit and the subsequent relapse. Finally, we need to know if the vulnerability of the prefrontal cortex to be impaired by drugs is related to cerebellar hyperactivity. 


\section{Acknowledgments}

This work was supported by grants from Secretaría de Estado de Universidades e Investigación del Ministerio de Educación y Ciencia (PR2006-0222), Ministerio de Ciencia e Innovación (PSI2008-01317/PSIC) and PIFI 3.3 CA Neurociencias UV-CA28. Authors acknowledge gratefully the linguistic revision by Shann Menard. 


\section{REFERENCES}

[1] Ito M. Cerebellar circuitry as a neuronal machine. Prog Neurobiol 2006; 78: 272303.

[2] Ramnani N. The primate cortico-cerebellar system: anatomy and function. Nat Rev Neurosci 2006; 7:511-22.

[3] Bower JM, Parson L. Rethinking “the lesser brain”. Sci Am 2003; 8: 51-57.

[4] Ito M. Mechanism of motor learning in the cerebellum. Brain Res 2000; 886: 23745.

[5] Sacchetti B, Baldi E, Lorenzini CA, Bucherelli C. Cerebellar role in fearconditioning consolidation. PNAS 2002; 99: 84-06-11.

[6] Sacchetti B, Scelfo B, Tempia F, Strata P. Long-term synaptic changes induced in the cerebellar cortex by fear conditioning. Neuron 2004; 42: 973-82.

[7] Schutter DJLG, van Honk J. An elecrophysiologial link between the cerebellum, cognition and emotion: frontal theta EEG activity to single-pulse cerebellar TMS. Neuroimage 2006; 33: 1227-31.

[8] Turner BM, Paradiso S, Marvel CJ, et al. The cerebellum and emotional experience. Neuropsychologia 2007; 45: 1331-41.

[9] Baumgartner T, Luzt K, Schidt CF, Jäncke L. The emotional power of the music. How music enhances the feeling of affective pictures. Brain Res 2006; 1075: 15164.

[10] Manzo J, Miquel M, Toledo R, Mayor JA, García IL, Aranda-Abreu G, Caba M, Hernandez ME. Fos expression at the cerebellum following non-contact arousal and mating behavior in male rats. Physiol Behav 2007; 93: 357-63.

[11] Holstege G, Georgiadis JR, Paans AM, Meiners LC, van der Graaf FH, Reinders AA. Brain activation during human male ejaculation. J Neurosci 2003; 23: 918593. 
[12] Xiang H, Lin C, Ma X et al. Involvement of the cerebellum in semantic discrimination: An fMRI study. Hum Brain Map 2003; 18: 208-14.

[13] Bastian AJ. Learning to predict the future: the cerebellum adapts feedforward movement control. Curr Op Neurobiol 2006; 16: 645-9.

[14] Petacchi A, Laird AR, Fox PT, Bower JM. Cerebellum and auditory function: an ALE meta-analysis of functional neuroimaging studies. Hum Brain Mapp 2005; 25:118-28.

[15] Fiez JA, Petersen SE, Cheney MK, Raichle ME. Impaired non-motor learning and error detection associated with cerebellar damage. A single case study. Brain 1992; 115: 155-78.

[16] Herrup K, Kuemerle B. The compartmentalization of the cerebellum. Annu Rev Neurosci 1997; 20:61-90.

[17] Larsell O. The morphogenesis and adult pattern of the lobules and fissures of the cerebellum of the white rat. J Comp Neurol 1952; 97: 281-356.

[18] Voogd J, Glickstein M. The anatomy of the cerebellum. Trends Neurosci 1998;21:370-375.

[19] Eccles JC, Llinas R, Sasaki K. Parallel fibre stimulation and the responses induced thereby in the Purkinje cells of the cerebellum. Exp Brain Res 1966; 1: 17-39.

[20] Ramon y Cajal S, Swanson N, Swanson L. Histology of the nervous system of man and vertebrates (History of neuroscience 6). New York: Oxford University Press; 1995.

[21] Ito M. The modifiable neuronal network of the cerebellum. Jpn J Physiol 1984; 34: 781-92.

[22] Apps R, Garwicz M. Anatomical and physiological foundations of cerebellar information processing. Nat Rev Neurosci 2005; 6: 297-11.

[23] Sommer MA. The role of the thalamus in motor control. Curr Op Neurobiol 2003; 13: $663-70$. 
[24] Middleton FA, Strick PL. Basal ganglia and cerebellar loops: motor and cognitive circuits. Brain Res Rev 2000; 31: 236-50.

[25] Anderson CM, Maas LC, Frederick BdB, et al. Cerebellar vermis involvement in cocaine-related behaviors. Neuropsychopharmacology 2006; 31: 1318-26.

[26] Snider RS, Maiti A, Snider SR. Cerebellar pathways to ventral midbrain and nigra. Exp Neurol 1976; 53: 714-28.

[27] Heath RG, Dempesy CW, Fontana CJ, Myers WA. Cerebellar stimulation: effects on septal region, hippocampus, and amygdala of cats and rats. Biol Psychiatry. 1978; 13: 501-29.

[28] Schweighofer N, Doya K, Kuroda S. Cerebellar aminergic neuromodulation: towards a functional understanding. Brain Res Rev 2004; 44: 103-16.

[29] Snider RS, Maiti A. Cerebellar contributions to the Papez circuit. J Neurosci Res. 1976; 2: 133-46.

[30] Ikai Y, Takada M, Shinonaga Y, Mizuno N. Dopaminergic and non-dopaminergic neurons in the ventral tegmental area of the rat project, respectively, to the cerebellar cortex and deep cerebellar nuclei. Neuroscience 1992; 51: 719-28.

[31] Ikai Y, Takada M, Mizuno N. Single neurons in the ventral tegmental area that project to both the cerebral and the cerebellar cortical areas by way of axons collaterals. Neuroscience 1994; 61: 925-34.

[32] Melchitzky DS, Lewis DA. Tyrosine hydroxylase- and dopamine transporterimmunoreactivity axons in the primate cerebellum. Neuropsychopharmacology 2000; 22: 466-72.

[33] Chadderton P, Margrie TW, Hausser M. Integration of quanta in cerebellar granule cells during sensory processing. Nature 2004; 428: 856-60.

[34] Llinás R. General discussion: radial connectivity in the cerebellar cortex: a novel view regarding the functional organization of the molecular layer. In The Cerebellum: New Vistas (Exp Brain Res Suppl 6) SL Palay and V Chan-Palay, Eds: 189-194. Springer Verlag. New York. 
[35] Bower JM. The organization of cerebellar cortical circuitry revisited. Implications for function. Ann NY Acad Sci 2002; 978: 135-55.

[36] Batchelor AM, Garthwaite J. Novel synaptic potentials in cerebellar Purkinje cells: probable mediation by metabotropic glutamate receptors. Neuropharmacology $1993 ; 32: 11-20$.

[37] Hirono M, Yoshioka T, Konishi S. GABA(B) receptor activations enhances mGluR-mediated responses at cerebellar excitatory synapses. Nat Neurosci 2001; 4: 1207-16.

[38] Oberdick J, Baader SL, Schilling K. From zebra stripes to postal zone: deciphering patterns of gene expression in the cerebellum. Trends Neurosci 1998; 21:383-90.

[39] Ito M, Sakurai M, Tongroach P. Climbing fiber induced depression of both mossy fibers responsiveness and glutamate sensitivity of cerebellar Purkinje cells. J Physiol 1982; 324: 113-34.

[40] Sakurai M. Synaptic modifications of parallel fiber-Purkinje cell transmission in in vitro guinea pig cerebellar slices. J Physiol 1987; 394: 463-80.

[41] Salin PA, Malenka RC, Nicoll RA. Cyclic AMP mediates a presynaptic form of LTP at cerebellar parallel fiber synapses. Neuron 1996; 16: 797-03.

[42] Lev-Ram V, Metha SB, Kleinfeld D, Tsien RY. Reversing cerebellar long-term depression. Proc Natl Acad Sci USA 2003; 100: 15989-93.

[43] Marcoli M, Maura G, Cervetto C, Giacomini C, Oliveri D, Candiani S, Pestarino M. Nitric oxide-evoked cGMP production in Purkinje cells in rat cerebellum: an immunocytochemical and pharmacological study. Neurochem Int 2006; 49: 68390.

[44] Chevaleyre V, Takahashi KA, Castillo PE. Endocannabinoid-mediated synaptic plasticity in the CNS. Ann Rev Neurosci 2006; 29: 37-76.

[45] Freund TF, Katona I, Piomelli D. Role of endogenous cannabinoids in synaptic signalling. Physiol Rev 2003; 83: 1017-66. 
[46] Diana MA, Levenes C, Mackie K Marty A. Short-term retrograde inhibition of GABAergic synaptic currents in rat Purkinje cells is mediated by endogenous cannabinoids. J Neurosci 2002; 22: 200-8.

[47] Kreitzer AC, Regehr WG Retrograde inhibition of presynaptic calcium influx by endogenous cannabinoids at excitatory synapses of Purkinje cells. Neuron 2001; 29: $1717-27$.

[48] Kreitzer AC, Regehr WG. Cerebellar depolarization-induced depression of inhibition is mediated by endogenous cannabinoids. J Neurosci 2001; 21: RC174.

[49] Kawamura Y, Fukaya T, Maejima T, Yoshida T et al. The $\mathrm{CB}_{1}$ cannabinoid receptor is the major cannabinoid receptor at excitatory presynaptic sites in the hippocampus and cerebellum. J Neurosci 2006; 26: 2991-01.

[50] Tsou K, Brown S, Sanudo-Pena MC, Mackie K, Walker JM. Immunohistochemical distribution of cannabinoid $\mathrm{CB}_{1}$ receptors in the rat central nervous system Neuroscience 1998; 83: 393-11.

[51] Skaper SD, Buriani A, Dal Tso R, et al. The ALIamide palmitoylethanolamide and cannabinoids, but not anandamide, are protective in a delayed postglutamate paradigm of excitotoxic death in cerebellar granule cells. PNAS 1996; 93: 398489.

[52] Galante M, Diana MA. Group I metabotropic glutamate receptor inhibit GABA release at interneuron-Purkinje cell synapses through endocannabinoid production. J Neurosci 2004; 24: 4865-74.

[53] Hashimotodani Y, Ohno-Shosaku T, Tsubokawa H et al. Phospholipase C-beta serves as a coincident detector through its $\mathrm{Ca} 2+$ dependency for triggering retrograde endocannabinoid signal. Neuron 2005; 45: 257-68.

[54] Brown SP, Safo PK, Regehr WG. Endocannabinoid inhibit transmission at granule cell to Purkinje synapses by modulating three types of presynaptic calcium channels. J Neurosci 2004; 24: 5623-31. 
[55] Safo PK, Regehr WG. Endocannabinoids control the induction of cerebellar LTD. Neuron 2005; 48: 647-59.

[56] Hyman SE, Malenka RC, Nestler EJ. Neural mechanisms of addiction: the role of reward-related learning and memory. Annu Rev Neurosci. 2006; 29: 565-98.

[57] Hyman SE. Addiction: a disease of learning and memory. Am J Psychiatry 2005; 162: 1414-22.

[58] Wolf ME, Sun X, Mangiavacchi S, Chao SZ, Psychomotor stimulants and neuronal plasticity. Neuropharmacology 2004; 47: 61-79.

[59] West AR, Floresco SB, Charara A, Rosenkranz JA, Grace AA. Electrophysiological interactions between striatal glutamatergic and dopaminergic systems. Ann NY Acad Sci 2003; 1003: 53-74.

[60] Carlezon WA, Nestler EJ. Elevated levels of GluR1 in the midbrain: a trigger for sensitization to drugs of abuse? TINS 2002; 25, 610-15.

[61] Kalivas P. Glutamate systems in cocaine addiction. Curr Opin Pharmacol 2004; 4: 23-9.

[62] Kalivas P, Volkow ND, Seamans J. Unmanageable motivation in addiction: A pathology in prefrontal-accumbens glutamate transmission. Neuron 2005; 45: 64750 .

[63] Lapish CC, Seamans JK, Chandler J. Glutamate-Dopamine co-transmission and reward processing in addiction. Alcohol Clin Exp Res 2006; 30: 1451-65.

[64] Kenny PJ, Markou A. The ups and downs of addiction: role of metabotropic glutamate receptors. Trends Pharmacol Sci 2004; 25: 265-272.

[65] Wolf ME. The role of excitatory amino acids in behavioural sensitization to psychomotor stimulants. Prog Neurobiol 1998; 54: 679-20.

[66] Kim JH, Venzina P. Metabotropic glutamate receptors are necessary for sensitization by amphetamine. NeuroReport 1998; 9: 403-6. 
[67] Kim JH, Venzina P. The mGlu2/3 receptor agonist LY379268 blocks the expression of locomotor sensitization by amphetamine. Pharmacol Biochem Behav 2002; 73: 333-37.

[68] Vanderschuren LJMJ, Kalivas P. Alterations in dopaminergic and glutamatergic transmission in the induction and expression of behavioural sensitization: a critical review of preclinical studies. Psychopharmacology 2000; 151: 99-20.

[69] Wang JQ, Fibuch EE, Mao L. Regulation of mitogen-activated proteine kinases by glutamate receptors. J Neurochem 2007; 100: 1-11.

[70] Valjent E, Corbillé AG, Bertran-Gonzalez J, Hervé D, Girault JA. Inhibition of ERK pathway or protein synthesis during reexposure to drugs of abuse erases previously learned place preference. PNAS 2006; 103: 2932-37.

[71] Carpenter-Hyland EP, Chandler J. Adaptive plasticity of NMDA receptors and dendritic spines: implications for enhanced vulnerability of the adolescent brain to alcohol addiction. Pharmacol Biochem Behav 2007; 86: 200-8.

[72] Maldonado R, Valverde O, Berrendero F. Involvement of the endocannabinoid system in drug addiction. TINS 2006; 29: 225-232.

[73] Jung KM, Mangieri R, Stapleton C, et al. Stimulation of endocannabinoid formation in brain slice cultures through activation of group I metabotropic glutamate receptors. Mol Pharmacol 2005; 68: 1196-02.

[74] Melis MR, Pistis M, Perra S, Muntoni AL, Pillolla G, Gessa GL. Endocannabinoids mediate presynaptic inhibition of glutamatergic transmission in rat ventral tegmental area dopamine neurons through activation of $\mathrm{CB} 1$ receptors. J Neurosci 2004; 24: 53-62.

[75] Cohen C SR141716, a central cannabinoid $\left(\mathrm{CB}_{1}\right)$ receptor antagonist, blocks the motivational and dopamine-realising effects of nicotine in rats. Behav Pharmacol 2002; 13: 451-63. 
[76] Hungund BL, Szakall I, Adam A, Basavarajappa BS, Vadasz C. Cannabinoid CB1 receptor knockout mice exhibit markedly reduced voluntary alcohol consumption. J Neurochem 2003; 84: 698-04.

[77] Thanos PK, Dimitrakakis ES, Rice O, Gifford A, Volkow ND. Ethanol selfadministration and ethanol conditioned place preference are reduced in mice lacking cannabinoid CB1 receptors. Behav Brain Res 2005; 164: 206-13.

[78] Ledent C, Unresponsiveness to cannabinoids and reduced addictive effects of opiates in $\mathrm{CB}_{1}$ receptor knockout mice. Science 1999; 280: 401-4.

[79] Navarro M, Carrera MR, Fratta W, Valverde O, Cossu G, Fattore L, Chowen JA, Gomez R, del Arco I, Villanua MA, Maldonado R, Koob GF, Rodriguez de Fonseca F. Functional interaction between opioid and cannabinoid receptors in drug self-administration. J Neurosci 2001; 21: 5344-50.

[80] Le Foll B, Goldberg SR, Rimonabant, a CB1 antagonist blocks nicotineconditioned place preference. NeuroReport 2004; 15: 2139-43.

[81] Gruol DL, Parsons KL, DiJulio N. Acute ethanol alters calcium signals elicited by glutamate receptors agonist and $\mathrm{K}+$ depolarization in culture cerebellar Purkinje neurons. Brain Res 1997; 773: 82-89.

[82] Tabakoff B, Hoffman P. Alcohol addiction: an enigma among us. Neuron 1996; 16: 909-912.

[83] Netzeband JG, Trotter C, Caguioa JN, Gruol DL. Chronic ethanol exposure enhances AMPA-elicited $\mathrm{Ca}^{2}+$ signals in the somatic and dendritic regions of cerebellar Purkinje neurons. Neurochem Int 1999; 35: 163-74.

[84] Botta P, Radcliffe RA, Carta M, et al. Modulation of GABAA receptors in cerebellar granule neurons by ethanol: a review of genetic and electrophysiological studies. Alcohol 2007; 41: 187-99.

[85] Carta M, Mameli M, Valenzuela F. Alcohol enhances GABAergic transmission to cerebellar granule cells via an increase in Golgi cell excitability. J Neurosci 2004; 24: $3746-51$. 
[86] Lee RS, Smith SS, Chapin JK, Waterhouse BD, et al. Effects of systemic and local ethanol on responses of rat cerebellar Purkinje neurons to iontophoretically applied $\gamma$-aminobutyric acid. Brain Res 1995; 687: 1-11.

[87] Ericson M; Haythornthwaite AR, Yeh PWL; Yeh HH. Brain-derived neurotrophic factor mitigates chronic ethanol-induced attenuation of $\gamma$-aminobutyric acid response in cultured cerebellar granule cells. J Neurosci Res 2003; 73: 722-30.

[88] Freund RK, Palmer MR. Ethanol depression of cerebellar Purkinje neurons firing involves nicotinic acetylcholine receptors. Exp Neurol 1997; 143: 319-22.

[89] Sanna PP, Simpson C, Lutjens R, Koob G. ERK regulation in chronic ethanol and withdrawal. Brain Res 2002; 948: 186-91.

[90] Barco A, Bailey CH, Kandel ER. Common molecular mechanism in explicit and implicit memory. J Neurochem 2006; 97: 1520-33.

[91] Asher O, Cunningham TD, Yao L, Gordon AS, Diamond I. Ethanol stimulates cAMP-responsive element(CREB)-mediated transcription via CRE-binding protein and cAMP-dependent protein kinase. J Pharmacol Exp Ther 2002; 301: 66-70.

[92] Offenhäuser N, Castelleti D, Mapelli L, et al. Increased ethanol resistance and consumption in Eps8 knockout mice correlates with altered actin dynamics. Cell 2006; 127: 213-26.

[93] Okamoto KI, Nagai T, Miyawaki A, Hayashi Y. Rapid and persistent modulation of actin dynamics regulates postsynaptic reorganization underlying bidirectional plasticity. Nat Neurosci 2004; 7: 1104-9.

[94] González S, Fernandez-Ruiz J, Di Marzo V, et al. Behavioral and molecular changes elicited by acute administration of SR141716 to delta-9tetrahydrocannabinol-tolerant rats: an experimental model of cannabinoid abstinence. Drug Alcohol Depend 2004; 74:159-70. 
[95] Rubino T, Forlani G, Viganò D, Zippel R, Parolaro D. Modulation of extracellular signal-regulated kinases cascade by chronic delta 9-tetrahydrocannabinol treatment. Mol Cell Neurosci. 2004; 25: 355-62.

[96] Hutcheson DM, Tzavara ET, Smadja C et al. Behavioral and biochemical evidence for signs of abstinence in mice chronically treated with delta-9tetrahydrocannabinol. Br J Pharmacol 1998; 125: 1567-77.

[97] Tzavara ET, Valjent E, Firmo C, et al. Cannabinoid withdrawal is dependent upon PKA activation in the cerebellum. Eur J Neurosci 2000; 12: 1038-46.

[98] Casu MA, Pisu C, Sanna A, et al. Effect of delta-9-tetrahydrocannabinol on phosphorylated CREB in rat cerebellum: An immunohistochemical study. Brain Res 2005; 1048: 41-7.

[99] Viganò D, Cascio MG, Rubino T, Chronic morphine modulates the contents of endocannabinoid, 2-Arachidonoyl Glycerol in rat brain.

Neuropsychopharmacology 2003; 28: 1160-67.

[100] Vinod KY, Yalamanchili R, Xie S, Cooper TB, Hungund BL. Effect of chronic ethanol exposure and its withdrawal on the endocannabinoid system. Neurochem Int 2006; 49: 619-625.

[101] Basavarajappa BS, Hungund BL. Role of the endocannabinoid system in the development of tolerance to alcohol. Alcohol Alcohol 2004; 40: 15-24.

[102] Klitenick MA, Tham CS, Fibiger HC. Cocaine and d-amphetamine increase c-fos expression in the rat cerebellum. Synapse 1995; 19: 29-36.

[103] Jenkins BG, Sanchez-Pernaute R, Brownell AL, Chen YCI, Isacson O. Mapping dopamine function in primates using pharmacologic magnetic resonance imaging J Neurosci 2004; 24: 9553-60.

[104] Jimenez-Rivera CA, Segarra O, Jimenez Z, Waterhouse BD. Effects of intravenous cocaine administration on cerebellar Purkinje cell activity. Eur $\mathbf{J}$ Pharmacol 2000; 407: 91-00. 
[105] Dietrich JB, Arpin-BottMP, Kao D, Dirrig-Groch S, Aunis D, Zwiller J. Cocaine induces the expression of homer $1 \mathrm{~b} / \mathrm{c}$, Homer $3 \mathrm{a} / \mathrm{b}$ and Hsp 27 proteins in rat cerebellum. Synapse 2007; 61: 587-94.

[106] Szumlinski KK, Kalivas PW, Worley PF. Homer proteins: implications for neuropsychiatric disorders. Curr Op Neurobiol 2006; 16: 251-57.

[107] Kammermeier PJ, Xiao B, Tu JC, Worley PF, Ikeda SR. Homer proteins regulate coupling of group I metabotropic glutamate receptor to N-Type calcium and MType potassium channels. J Neurosci 2000; 20: 7238-45.

[108] Ravindram CRM, Mehta AK, Ticku MK. Effect of chronic administration of ethanol on the regulation of tyrosine kinase phosporylation on the $\mathrm{GABA}_{\mathrm{A}}$ receptor subunits in the rat brain. Neurochem Res 2007; 32: 1179-87.

[109] Vanderschuren LJ, Everitt BJ. Behavioral and neural mechanisms of compulsive drug seeking. Eur J Pharmacol 2005; 526:77-88.

[110] Everitt BJ, Robbins TW. Neural systems of reinforcement for drug addiction: from actions to habits to compulsion. Nat Neurosci 2005; 8:1481-9.

[111] Robinson TE, Berridge KC. The psychology and neurobiology of addiction: an incentive-sensitization view. Addiction 2000; 95 Suppl 2:S91-117.

[112] Robinson TE, Berridge KC. Incentive-sensitization and addiction. Addiction 2001; 96:103-14.

[113] Robinson TE, Berridge KC. Addiction. Annu Rev Psychol. 2003; 54:25-53.

[114] O’Brien CP, Childress AR, Ehrman R, Robbins SJ. Conditioning factors in drug abuse: Can they explain compulsion? J. Psychopharmacol. 1998; 12: 15-22.

[115] Borgland SL, Malenka RC, Bonci A. Acute and chronic cocaine-induced potentiation of synaptic strength in the ventral tegmental area: electrophysiological and behavioral correlates in individual rats. J Neurosci. 2004; 24: 7482-90. 
[116] Beurrier C, Malenka RC. Enhanced inhibition of synaptic transmission by dopamine in the nucleus accumbens during behavioral sensitization to cocaine. $\mathrm{J}$ Neurosci. 2002; 22: 5817-22.

[117] Vezina P. Sensitization of midbrain dopamine neuron reactivity and the selfadministration of psychomotor stimulant drugs. Neurosci Biobehav Rev 2004; 27 : 827-39.

[118] Rubino T, Viganó D, Massi P, Parolaro D. Celullar mechanism of delta-9tetrahydrocannabinol behavioural sensitization. Eur J Neurosci 2003; 17: 325-30.

[119] Rodriguez de Fonseca F, Gorriti MA, Fernandez Ruiz JJ, Palomo, T, Ramos J. Downregulation of rat cannabinoid binding sites alter chronic delta-9tetrahydrocannabinol treatment. Pharmacol Biochem Behav 1994; 47: 33-40.

[120] Cunningham CL, Noble D. Conditioned activation induced by ethanol: Role in sensitization and conditioned place preference. Pharmacol Biochem Behav 1992; 43: 307-13.

[121] Phillips TJ, Shen EH. Neurochemical bases of locomotion and ethanol stimulant effects. Int Rev Neurobiol 1996; 39: 243-82.

[122] Miquel M, Font L, Sanchis-Segura C, Aragon CMG. Neonatal administration of monosodium glutamate prevents the development of ethanol-but not psychostimulant-induced sensitization: a putative role of the arcuate nucleus. Eur J Neurosci 2003; 17: 2163-70.

[123] Bhargava HN, Kumar S. Sensitization to locomotor stimulant effect of cocaine modifies the binding of $\left[\mathrm{H}^{3}\right] \mathrm{MK}-801$ to brain regions and spinal cord of the house. Gen Pharmacol 1999; 32: 359-63.

[124] Bhargava HN, Kumar S. Sensitization to the locomotor stimulant activity of cocaine is associated with increases in nitric oxide synthase activity in brain regions and spinal cord. Pharmacology 1997; 55: 292-8. 
[125] Itzhak Y. Modulation of cocaine- and methamphetamine-induced behavioral sensitization by inhibition of brain nictric oxide synthase. J Pharmacol Exp Ther 1997; 282: 521-7.

[126] Itzhak Y, Ali SF, Martin JL, Black MD, Huang PL. Resistance of neuronal nitric oxide Synthase-deficient mice to cocaine-induced locomotor sensitization. Psychopharmacology 1998; 140: 378-86.

[127] Couceyro P, Pollock KM, Drews K, Douglass J. Cocaine differentially regulates activator protein-1mRNA levels and DNA-binding complexes in the rat striatum and cerebellum. Mol Pharmacol 1994; 46: 667-76.

[128] Barik S, Beaurepaire R. Dopamine 3 modulation of locomotor activity and sleep in the nucleus accumbens and in lobules 9 and 10 of the cerebellum. Prog Neuropsychopharmacol Biol Psychiatry 2005; 29: 718-26.

[129] Tiffany ST. A cognitive model of drug urges and drug-use behavior: role of automatic and nonautomatic processes. Psychol Rev 1990; 97:147-68.

[130] Di Ciano P, Everitt BJ. Neuropsychopharmacology of drug seeking: Insights from studies with second-order schedules of drug reinforcement. Eur J Pharmacol 2005; 526: $186-98$.

[131] Schultz W. Multiple Dopamine Functions at Different Time Courses. Annu Rev Neurosci 2007; 30:259-88.

[132] Salamone JD, Correa M, Farrar A, Mingote SM. Effort-related functions of nucleus accumbens dopamine and associated forebrain circuits.

Psychopharmacology 2007; 19: 461-82.

[133] Grant S, London ED, Newlin DB, et al. Activation of memory circuits during cueelicited cocaine craving. PNAS 1996; 93: 12040-5.

[134] Volkow N, Wang G-J, Fowler JS, et al. Association of methylphenidate-induced craving with changes in right striato-orbitofrontal metabolism in cocaine abusers: Implications in addiction. Am J Psychiatry 1999; 156: 19-26. 
[135] Volkow N, Wang G-J, Ma Y, et al. Expectations enhances the regional brain metabolic and the reinforcing effects of stimulants in cocaine abusers. J Neurosci 2003; 23: 11461-68.

[136] Bonson KR, Grant SJ, Contoreggi MD, et al. Neural systems and cue-induced cocaine craving. Neuropsychopharmacology 2002; 26: 376-86.

[137] Schneider F, Habel U, Wagner M et al. Subcortical correlates of craving in recently abstinent alcoholic patients. Am J Psychiatry 2001; 158: 1075-83.

[138] Wang GN, Volkow ND, Fowler JS et al. Regional Brain metabolic activation during craving elicited by recall of previous drug experience. Life Sci 1999; 64: 775-84.

[139] Duvauchelle CL, Ikegami A, Asami S, Robens J, Kressin K, Castaneda E. Effects of cocaine context on NAcc dopamine and behavioral activity after repeated intravenous cocaine administration. Brain Res. 2000; 862:49-58.

[140] Hemby SE, Co C, Koves TR, Smith JE, Dworkin SI. Differences in extracellular dopamine concentrations in the nucleus accumbens during response-dependent and response-independent cocaine administration in the rat. Psychopharmacology $1997 ; 133: 7-16$.

[141] Hubert V, Beauniex H, Chételat G, et al. The dynamic network subserving the three phases of cognitive procedural learning. Hum Brain Mapp 2007; 28: 141529.

[142] Fliessbach K, Trautner P, Quesada CM, Elger C, Weber B. Cerebellar contributions to episodic memory encoding as revealed by fMRI. Neuroimage 2007; 35: 1330-7.

[143] Yin HH, Knowlton JK. The role of the basal ganglia in habit formation. Nat Rev Neurosci 2006; 7: 464-476.

[144] Jentsch JD, Taylor JR. Impulsivity resulting from fronto-striatal dysfunction in drug abuse: implications for the control of behaviour by reward-related stimuli. Psychopharmacology 1999; 146: 373-90. 
[145] Bechara A. Decision making, impulse control and loss of willpower to resist drugs: a neurocognitive perspective. Nat Neurosci 2005; 8: 1458-63.

[146] Volkow ND, Fowler JS, Wang GJ. The addicted human brain viewed in the light of imaging studies: brain circuits and treatment strategies. Neuropharmacology 2004; 47: 3-13.

[147] Goldstein RZ, Volkow ND. Drug addiction and its underlying neurobiological bases: neuroimaging evidence for the involvement of the frontal cortex. Am J Psychiatry 2002; 159:1642-52.

[148] Montague PR, Hyman SE, Cohen JD. Computational roles for dopamine in behavioural control. Nature 2004; 431: 760-7.

[149] Kelly RM, Strick PL. Cerebellar loops with motor cortex and prefrontal cortex of nonhuman primates. J Neurosci 2003; 23: 8432-44.

[150] Ito M. Control of mental activities by internal models in the cerebellum. Nat Rev Neurosci 2008; 9:304-13.

[151] Callu D, Puget S, Faure A, Guegan M, El Massioui N. Habit learning dissociation in rats with lesions to the vermis and the interpositus of the cerebellum. Neurobiol Dis 2007; 27: 228-37.

[152] Bobée S, Mariette E, Treblay-Leveau H, Caston J. Effects of early midline cerebellar lesion on cognitive and emotional functions in the rat. Behav Brain Res 200; 112: 107-17.

[153] Fuchs RA, Evans A, Parker MP, See RE. Differential involvement of orbitofrontal cortex subregions in conditioned cues-induced and cocaine-primed reinstatement of cocaine seeking in rats. J Neurosci 2004; 24: 6600-10.

[154] Hester R, Garavan H. Executive dysfunction in cocaine addiction: Evidence for discordant frontal, cingulated, and cerebellar activity. J Neurosci 2004; 24: 11017 22. 
[155] Goldstein RZ, Tomasi D, Alia-Klein N, Zhang L, Telang F, Volkow ND. The effect of practice on a sustained attention task in cocaine abusers. Neuroimage 2007; 35: 194-206.

[156] Desmond JE, Chen SH, DeRosa E, Pryor MR, Pferfferbaum A, Sullivan EV. Increase frontocerebellar activation in alcoholics during verbal working memory: an fMRI study. Neuroimage 2003; 19: 1510-20.

[157] Bolla KI, Eldreth DA, Matochik JA, Cadet JL. Neural substrates of faulty decision-making in abstinent marijuana users. Neuroimage 2005; 26: 480-92.

[158] Martin-Sölch C, MagyarS, Künig G, Missimer J, Schultz W, Leendersw KL. Changes in brain activation associated with reward processing in smoker and nonsmokers. A positron emission tomography study. Ex Brain Res 2001; 139: 278-86. 
(Insert in pag 17)

Table 1. Drug molecular mechanisms in the cerebellum. The table sums up drug-induced molecular mechanisms discussed in the text.

\begin{tabular}{|c|c|c|c|}
\hline & Acute & Chronic & Under withdrawal \\
\hline \multicolumn{4}{|l|}{ Ethanol } \\
\hline \multirow[t]{2}{*}{ Glutamate function } & $\begin{array}{l}\text { Depression of } \mathrm{Ca}^{2+} \text { signalling linked to AMPAR in Purkinje } \\
\text { neurons }(30-100 \mathrm{mM})^{1}\end{array}$ & $\begin{array}{l}\text { Increase in } \mathrm{Ca}^{2+} \text { signalling linked to } \\
\text { AMPAR in Purkinje neurons }{ }^{\mathrm{I}}\end{array}$ & \\
\hline & $\begin{array}{l}\text { Enhancement in } \mathrm{Ca}^{2+} \text { curremt to mGLuR agonists in } \\
\text { Purkinje neurons }(10 \mathrm{mM})^{1}\end{array}$ & & \\
\hline \multirow[t]{3}{*}{ GABA function } & $\begin{array}{l}\text { Increase in GABAergic inhibition of granule cell via } \\
\text { excitation of Golgi cells }{ }^{2}\end{array}$ & $\begin{array}{l}\text { Reduction in responsiveness to extemally } \\
\text { applied GABA in granule cells }{ }^{4}\end{array}$ & \\
\hline & $\begin{array}{l}\text { Increase in GABA-mediated inhibitory responses of Purkinje } \\
\text { neurons }{ }^{3}\end{array}$ & & \\
\hline & $\begin{array}{l}\text { Nicotine enhances ethanol-induced depression of Purkinje } \\
\text { neurons }{ }^{5}\end{array}$ & & \\
\hline \multirow[b]{2}{*}{$C B_{1}$ function } & & Accumulation of endocannabinoids ${ }^{13}$ & \\
\hline & & Reduction in $\mathrm{CB}_{1}$ density ${ }^{13}$ & \\
\hline \multirow{2}{*}{$\begin{array}{l}\text { Intracelullar } \\
\text { pathways and } \\
\text { associated gene } \\
\text { expression }\end{array}$} & Loss of F-actin ${ }^{8}$ & Down-regulation of ERK activation " & Up-regulation of ERK activation ${ }^{6}$ \\
\hline & & $\begin{array}{l}\text { Induction of cAMP-dependent gene } \\
\text { expression regulated by CREB and } \\
\text { PKA }^{7}\end{array}$ & \\
\hline
\end{tabular}

\section{Della-9-THC}

Imtracelvllor
pathways and
associated gene
expression

Down-regnlation ERK activation
Decrease in CREB expression
Up-rcgulation of adoureyclese activity

UP-rgenlation of the eAMP-PKA petheray II

Psychostimulants

Decrease in CREB expression ${ }^{\text {tz }}$

Suppressim of spontaneres firing and ghummite-indured axtivation of Pukinje cells ${ }^{16}$

Adrenergic agonist increases focaine-dopendent suppression of Parkinje nearons ${ }^{14}$
Increase in FOS expression at the grambar layer ${ }^{\text {ss }}$

Increase in Homer Ib/c and 3/b expression in Pukinie neurons to

${ }^{1}$ Reference $[81] ;{ }^{2}$ Reference $[85] ;{ }^{3}$ Reference [86]; ${ }^{4}$ Reference $[87] ;{ }^{5}$ Reference [88]; ${ }^{6}$ Reference [89]; ${ }^{7}$ Reference [91]; "Reference [92]; Reference [95]; ${ }^{18}$ Refenence [96]; ${ }^{11}$ Refenence [97]; ${ }^{12}$ Reference [98]; ${ }^{13}$ References [99,100,101]; ${ }^{14}$ Reference [104]; ${ }^{15}$ Reference [102];

is Reference [105] 


\section{LEGENDS}

\section{Figure 1. A dorsal view of the rat cerebellum.}

The geometry is an ellipse with a central region known as the vermis, and two hemispheres at each side.

\section{Figure 2. Lobules and cortical layers in the cerebellum}

a) A sagittal slice of the rat cerebellum $(40 \mu \mathrm{m})$, where cortical layers and white matter (wm) are shown. The disposition of the transverse fissures on the surface forms 10 different lobules at the cerebellar cortex. b) An enlargement of Lobule 7. The cerebellar cortex has three different layers: the external layer or the Molecular Layer (ML), the middle layer or Purkinje Perikarya Layer (PL) composed of Purkinje cell somas, and the bottom layer that is referred to as the Granule Cell (GL) Layer.

\section{Figure 3. Basic cerebellar circuitry.}

The cerebellar circuitry has two main afferent pathways. Mossy fibers (MF) from the brainstem and the spinal cord target the glomerulus at the granular layer and make synapses with granular cells (Gr). Within the glomerulus, the dendrites of Gr cells receive excitatory synapses from MF axon terminals and an inhibitory (-) input from the Golgi cell (G) axons. The axons of granule cells bifurcate into the parallel fibers (PLF) in the molecular layer and they supply glutamatergic synapses $(+)$ to the dendritic tree of Purkinje cells (P). The PLF make excitatory synapses not only with the distal dendrites of the Purkinje cells, but also those of inhibitory stellate (S) and basket cells (B). The other afferent pathway to the cerebellar cortex is the climbing fibers (CF), which arise from the inferior oliva and make several excitatory synapses with a single Purkinje neuron. 
Figure 4. Drug action sites in the cerebellum. See table 1 for further explanation.

Figure 5. Working hypothesis. Functional and structural modifications induced by drugs in the cerebellum may enhance the susceptibility of fronto-cerebellar circuitry to be changed by repeated drug exposure. Drug-induced cerebellar hyper-responsiveness can cause a functional reorganization of the fronto-cerebellar network and reduce the executive control of the prefrontal cortex on behaviour. One can expect the pattern of cerebellar hyperactivity and prefrontal hypoactivity to follow a temporal gradient, the cerebellum being more important as the exposure to drugs is repeated. The top and bottom bars show a white (minimum)-dark (maximum) gradient to express changes in the executive control of the prefrontal cortex (top) and responsiveness (bottom). 
Figure 1

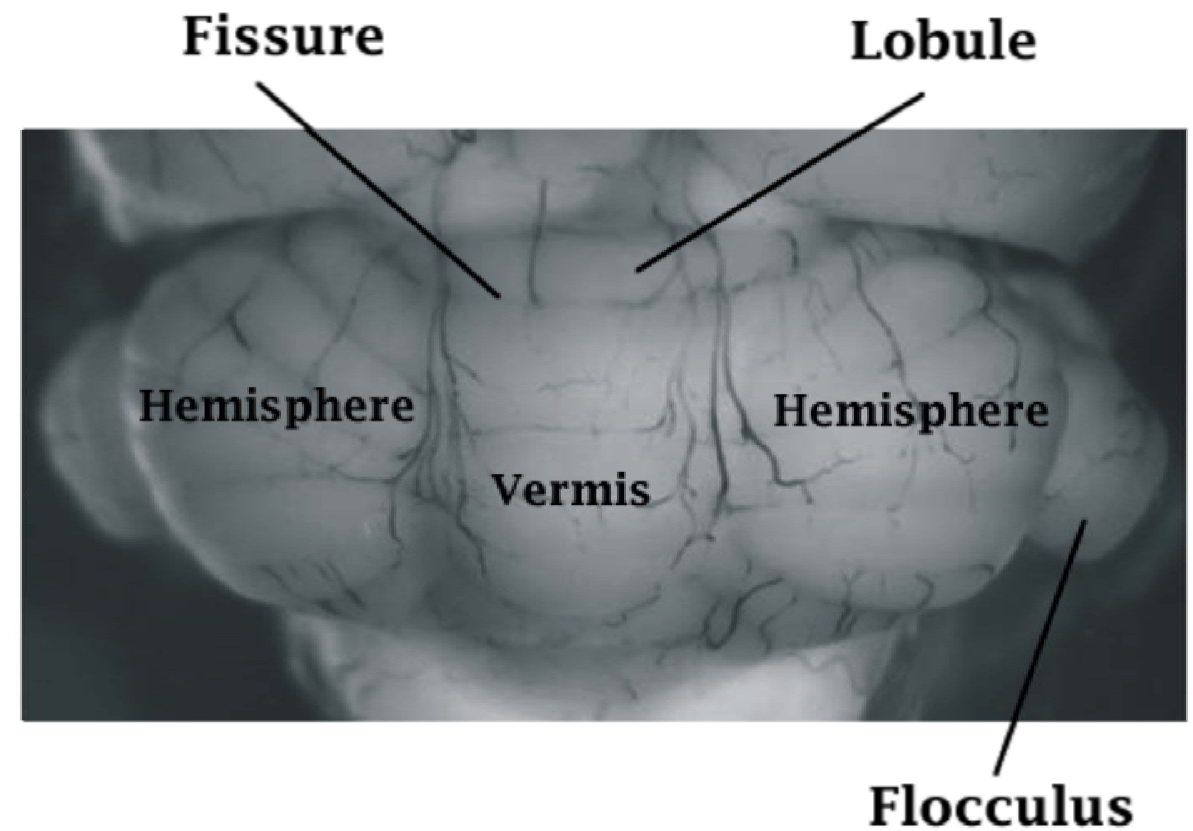

Figure 2 

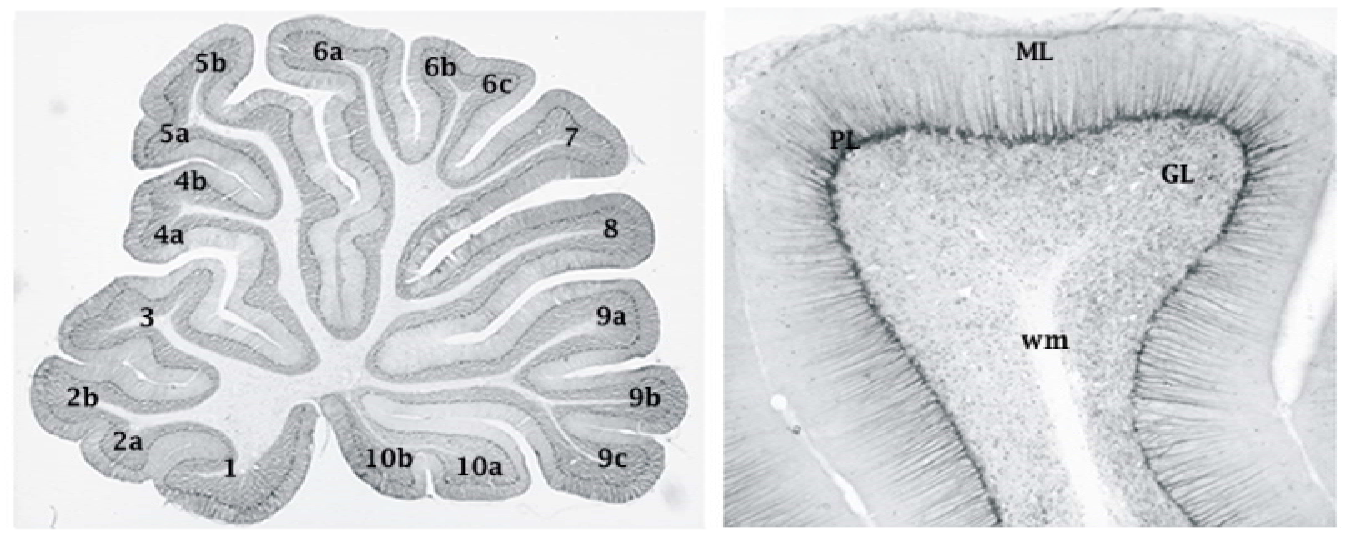

Figure 3 


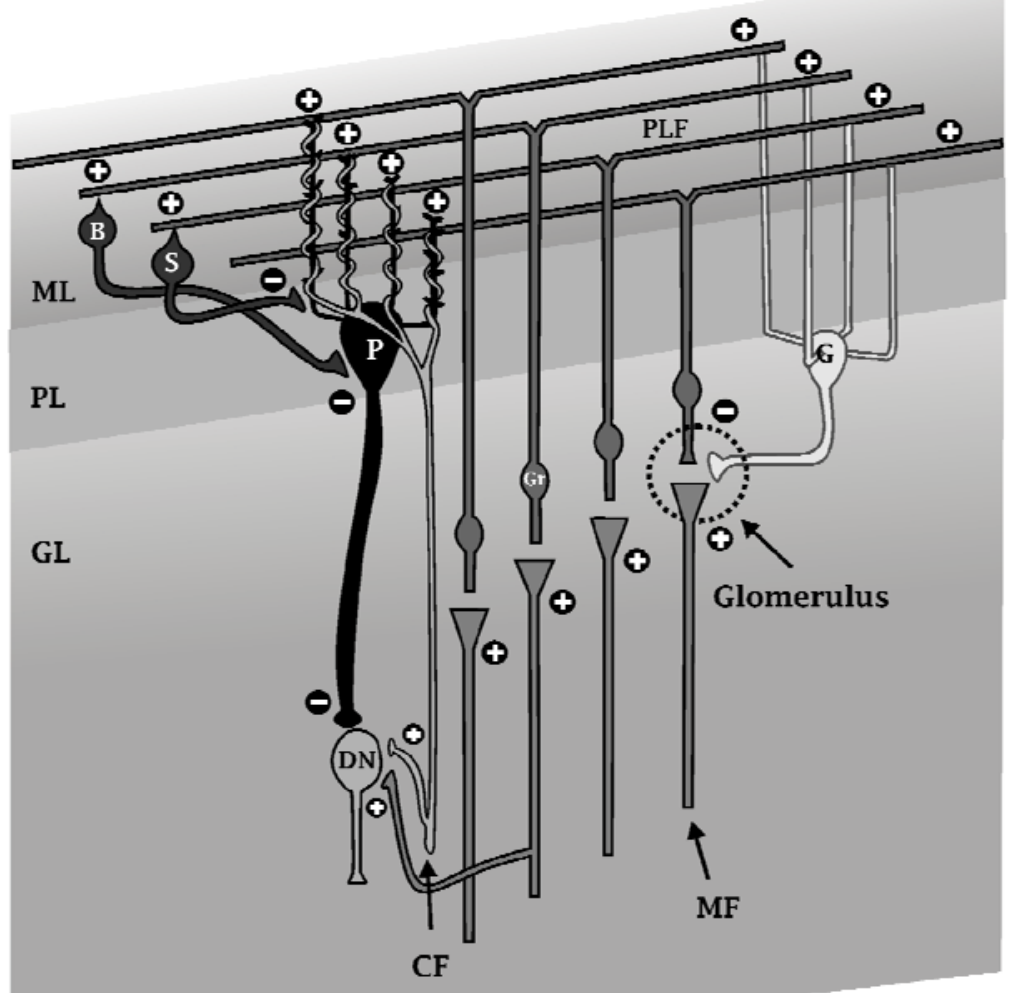

Figure 4 


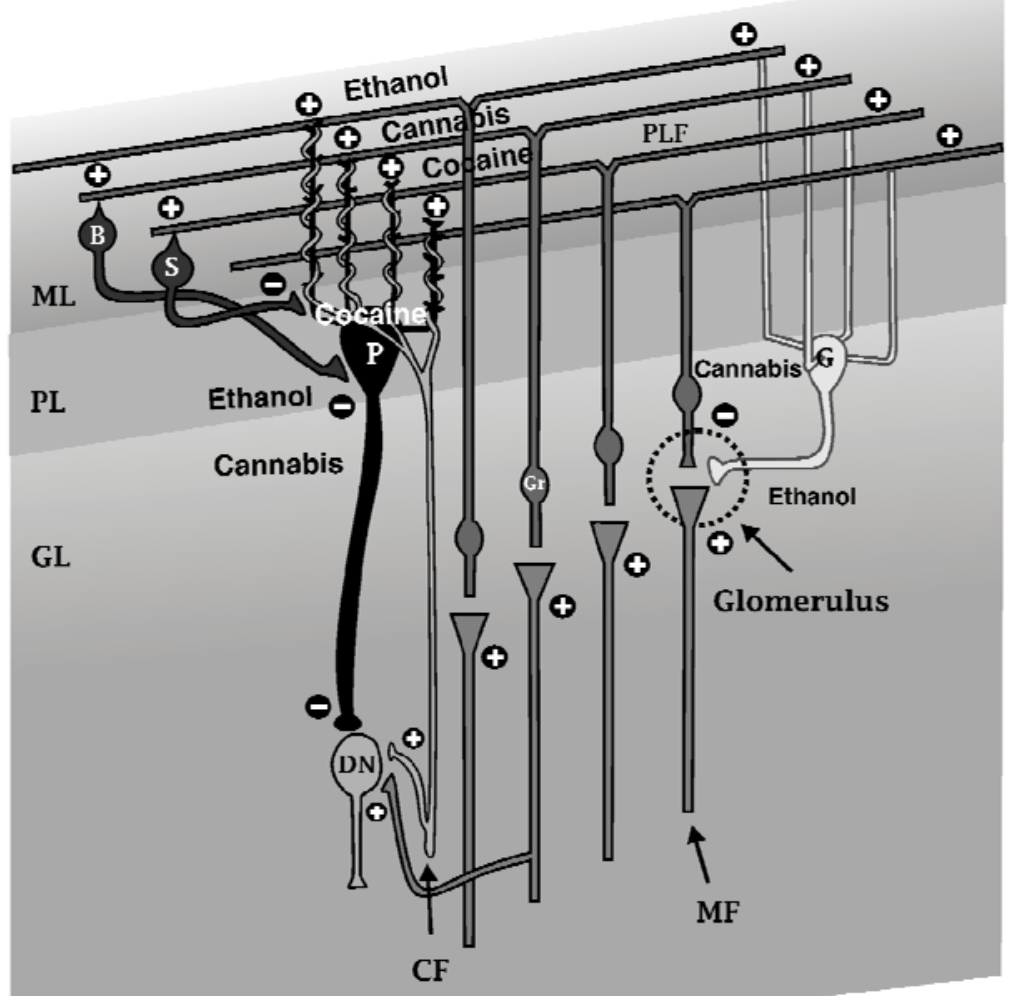

Figure 5 
executive control

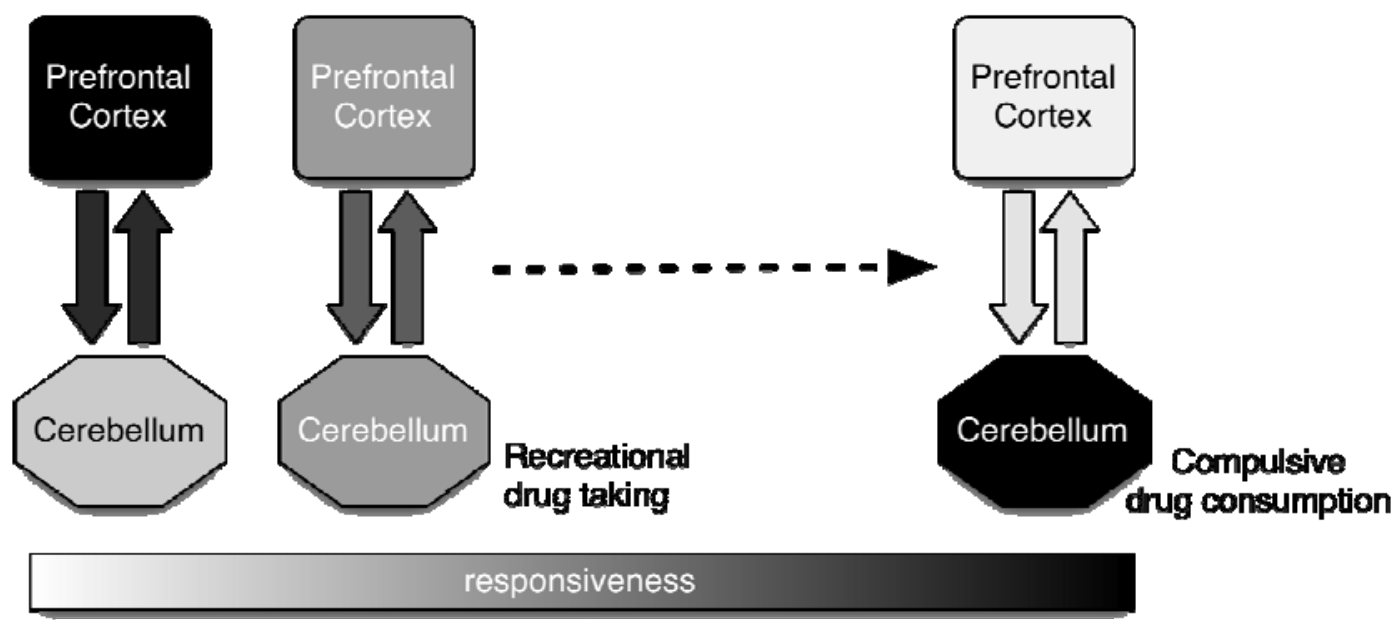


